\title{
Educational leadership approaches and trends
}

\author{
Sefi Peleg \\ Universitatea Babeş-Bolyai, Cluj-Napoca
}

Email address:

sefip@013.net (S. Peleg)

\section{To cite this article:}

Sefi Peleg. Educational Leadership Approaches and Trends. Education Journal. Vol. 1, No. 1, 2012, pp. 9-14.

doi: $10.11648 /$ j.edu. 20120101.13

\begin{abstract}
Managers have different management styles. No manager is the same as another, or as any of the classical management styles that are defined in the literature. It is very hard to relate to a permanent style of management. During a career a manager can experience several situations. The most active managers - principals - are the transformational leaders who encourages the staff to achieve beyond the personal interest to advance a common goal stemming from it. School managers face dilemmas since autonomous school managers have responsibility and authority to channel the money at their disposal as they see fit. According to the claim that there are countless definitions of the word 'leadership' the term can be divided into two main categories: Inborn attributes and acquired attributes.
\end{abstract}

Keywords: Management styles, School, Self-management, Leadership

\section{Introduction}

Managers have different management styles. No manager is the same as another, or as any of the classical management styles that are defined in the literature. This chapter will examine several typical management styles in the education system. The manager usually has diverse attributes that are suitable to diverse types of management and each person has differing dominant attributes. Typical$\mathrm{ly}$, there is one that is prominent relative to other styles, but one can also find at least one additional administrative style. Cheng (1993) calls it a stylistic web. In fact, each principal has a unique style. Various studies have found that the typical management style may vary considerably with change in the place of work. Some of the factors that affect the management style include physical characteristics of the school, its location in the city or in the periphery, its seniority as an institution, the extent to which there are educational routines, the stability of the teaching staff, the economic and social standing of most students, the degree of parental involvement of parents in educational activity, significant events that happened in the past, the circumstances of the principal's appointment (from within the school or appointed from outside) and many others.

Hence it is very hard to relate to a permanent style of management.

\section{Body of Paper}

In recent years, the Ministry of Education and local authorities are encouraging principals to adopt selfmanagement: a trend of moving administrative powers to the central authority's pedagogical and local schools. This trend is to give schools authority in decision-making on matters that they previously lacked, thus creating an autonomous organizational environmental with autonomous schools. The Ministry of Education has, for more than a decade, encouraged the establishment of unique schools and the conversion of existing schools to having broad autonomy in pedagogic and budgetary matters. School funding was by the State, and by local authorities of high schools, but administration is independent. The new policy was welcomed by groups of parents and educators, mainly based in the established suburbs. Perception of school autonomy was developed, inter alia, in the United States. One type of such schools is called Charter Schools. These schools follow a concession by the local education authority, whose terms and its denial are determined by special legislation in each of the states in the United States that decides to allow these schools. Until the end of 1998 more than 1,000 autonomous charter schools were established in 33 states, who delivered the required legislation. In December 1998 the first systematic research was published (Ministry of Education, 1998) based on a sample of 17 autonomous schools in the State of California. The research team was headed by education researcher Stuart Wells.

In Israel the perception of school autonomy gained a foothold in the Ministry of Education and amongst many 
educators and parents. A summary of the findings from California is therefore presented here. In Israel the conditions for the operation of autonomous schools are different - autonomy finds expression in the franchise afforded by the State or the local authority, but the convention between the Ministry of Education and the local authority enables the school to pool the financial resources from various sources such as the Ministry of Education, the local authority, the parents, donations and so on (Ministry of Education, 1998).

Autonomy of the institution is in fact autonomy in which role holders there take decisions and execute them during their work, without needing the agreement of higher levels. This is the degree of autonomy afforded them. Others, playing a similar role, take a different measure of independence when filling their roles in an organization.

The difference in employees' autonomous behavior is thus personal and inter-personal. To investigate the differences regarding the degree of independence and initiative the employees/teachers adopt, it would be extremely effective to define the employee's/teacher's autonomy as the degree to which he is authorized or sees himself authorized to initiate, decide and execute decisions independently, without the need for confirmation from higher ranks. An employee/ teacher who does not work independently and does not initiate, but functions according to instructions given shows little autonomous behavior, while such a person who works independently is free to alter existing behaviors to suit conditions and limit variables, showing a great deal of autonomous behavior.

One can formulate a number of the premises regarding demonstrating autonomy amongst professionals in organizations in general and in schools in particular. Autonomous behavior in expressed in the type of organizational behavior. An employee's behavior is related first and foremost, to his desire to win it. Autonomy is not forced on an employee who does not want it. Different people may display different amounts of autonomous behavior regarding a particular involvement.

In recent years researchers in Israel have emphasized events in autonomous schools and have tried to examine the processes occurring there.

What is a "self-management school" in Israel? This is a school enjoying maximum flexibility in using a diversity of resources available to improve and advance his pedagogic achievements.

Underlying self-management is a broad consensus regarding delegating economic measures, authority in personnel organizational, and financial issues which are all internal. Its administrative culture is flexible, adapting itself quickly to the new information and to internal and external changes in the organizational environment, quickly and effectively. Such a school will have the responsibility to report to the central authority on the objectives it set itself, the way it allocated its resources and determined the order of priorities, and, of course, the educational and social outputs (Friedman, 1995).
Education systems in diverse countries, especially England and USA, recently adopted the independent school style (Friedman, 1995).

In 1986 the Israeli Ministry of Education and culture decided to apply the experiment of transferring elementary schools to autonomous management. The experiment started in nine schools in four Ministry of Education districts: the North, Haifa, central Israel and the south (Friedman, 1995).

Autonomous school administration falls within the boundaries of administrative authority, which are defined with five main limitations. The official national curriculum is obligatory in autonomous schools, which function according to the education laws, regulations and rules. Personnel in these schools shall be according to work agreements with the teachers' associations, with other employment organizations, and according to the instructions of the Ministry of Education CEO. The number of weekly hours of study shall not be less or the length of the day shorter than that determined from time to time by the Ministry. Autonomous schools are inspected by the local authorities, the Ministries of Education and the Interior, coordinated with the Union of Local Authorities in Israel. Administrative boundaries, the boundaries of the autonomous administrative authority, have five major restrictions imposed by the official State curriculum schools' autonomous management. Autonomous schools run according to the education laws, regulations and rules. Personnel management autonomous schools will need to work with teachers and other employees in the organization and under the guidance of the Ministry of Education CEO. The number of study hours will vary, and the weekly hours of studies will not be less than is required by the Ministry of Education. Autonomous management school work, the guidance, and the control shall be by the local authority's financial officer, the Ministry of Education and the Ministry of the Interior. Autonomous school principals face dilemmas since they have the responsibility and the authority to channel the money at their disposal as they see fit. The premise is that the school is run by professional accountants. However, there are mechanisms to monitor and control that test the school activity and budgeting in particular. A school principal must maneuver between his wishes, and those of the teachers, parents, community, the local authority and the Ministry of Education. All are involved in preparing the budget and diverting the money to different objectives. Conflicts sometimes occur between the partners. The principal must navigate between all of them, find the best way to satisfy all, and assure primarily the school's products. He can attain high achievements through the autonomy he holds. The potential embedded in the authority to manage the budget is great and a principal who knows how to work with his budget, recruit outside money and channel the input to the relevant channels will feel that the authority he holds raises the threshold of thought and activity.

Autonomous management schools are flexible in their use of most resources. Autonomous management has a 
positive effect on achievement compared to the standard management of schools.

The Ministry of Education report on the students who attended autonomous schools finds the average score for English was 30 points higher than the average in other schools. Science and math students in state schools received two points more than regular schools.

Moreover. in the autonomous State religious and Arab schools the students received higher scores than those in regular schools, especially in English (a score of 66 compared to 61, and 68 compared to 63 in the Arab sector. In the other districts of the Ministry of Education the improvement was particularly noted in the Tel Aviv area, where there was a four point improvement on average for self-management schools.

Research conducted by the Ministry of Education for 1993-1994 compared the students' grades in 637 autonomous elementary schools to 809 standard elementary schools. No significant difference was found between the distribution between strong and weak schools in both groups about $33 \%$ of the self-management schools were defined as not established compared to $26 \%$ of regular "schools". However, only a small proportion $(6 \%)$ of the autonomous schools are Arab and Druze schools, accounting for $21 \%$ of all schools.

The advantages of the autonomous schools are obvious not only in the scores. For example, $74 \%$ of the teachers at the autonomous schools reported that they use a computer, compared to $67 \%$ of the teachers in schools that are not autonomous. A slightly larger proportion of the teachers in autonomous schools compared to other schools testified that the school is well-managed, the principal has pedagogic authority, and the teachers are involved in the decisionmaking process. The percentage of teachers who stated that they are satisfied with their work was higher in autonomous schools - $78 \%$ compared to $76 \%$ in other schools.

\subsection{Leadership in Education}

Educational reality, existing in a dynamic changing environment, arouses the need for leadership that charts a path and calls for activity and cooperation. Huber (2004) states that school's main role is developing and promoting its quality, so preparing the school leaders in many countries is of great importance. This concept led to developing comprehensive plans for educational leadership. Ben-Zvi (2003) claims that the goals underlying educational leadership include increasing the ability of employees to solve problems under the leader's initiative and to construct and encourage those led to realize their personal potential, transcend the mediocre and move to high levels of learning and commitment.

Carmi (2004) states that the educational leadership in general and the teacher as a leader in particular, must lead to developing educational learning materials, to change and to effective classroom activity.

The teacher's leadership leading to learning: Wagner (2003) investigated the processes of change and helped them to develop in many schools in the United States and abroad, formulating the "Action theory of change" - to alter and improve the students' learning. The theory consists of theoretical ideas that have developed from action, experimentation and error, and from reflection. Wagner (2003) claims leadership is required that produces constructivist learning i.e. learning as a process of structuring where the teacher has no superiority compared to that of the student. Information is personal structuring. The teacher's leadership, therefore, may lead to constructivist learning and improved learning.

Such learning can occur when there is a shared vision of the learning objectives, teaching methods, learning topics and methods of evaluation, that is, a shared vision adapted to global changes which will include the main skills required to prepare each student to work. The teachers will come to a shared vision through experimentation, exposure to different teaching methods, and through peer training. They will eventually develop skills and expertise that they can impart to others. They should also understand that there is a need for urgent change - change in the essence of the work, adult expectations of the community, about what to teach, how to teach and motivate students to learn. All students today need diverse skills such as the ability to solve problems, work in a team and study independently, and must be prepared for higher standards and ongoing learning. Learning no longer depends on respect for authority and the fear that therefore the school teachers establish educational forums for discussion where everyone, not only education employees, can get together to understand how society changed and what effects this change has on education and parenting; to meet and discuss various information, not just the information that deals with dropping out or successful tests. They hear the skills required today in places of work. They must hear from youth who have just finished their studies how little school trained them for the future; and hear from students about the lack of respect on the part of teachers and loneliness they feel in school. Data collection requires a long time, but it can arouse the necessary discourse with the teachers who may try new ways to conduct a class. A relationship is building a guarantee based on mutual respect and trust: many high school students in most schools claim that their schools are alienated bureaucracies and not communities who care for them. In theory, most educators agree about the importance of respect in the classroom. Educational leaders might clarify the teachers' and students' unequivocal need to create an atmosphere of respect. They should clarify that it is nonnegotiable and is the responsibility of all. How to create an atmosphere of respect can start with student discussion groups - initiating conversations in small groups on the desired behavior from the teachers and students. Teams should be established in which teachers learn how to work more collaboration with regular discussions, troubleshooting in small groups. Gradually, the preference for individual work will make place for team achievements. From discussion on the curriculum and students' work the teachers 
can move to mutual observations in the classroom, and later even give each other feedback on ways of teaching. Wagner (2003) believes eventually colleague learning rather than measurement and evaluation by educational leaders is the key to improve teaching and is the heart of the effort to improve the schools. Educational leaders will help establish this approach if they demonstrate respectful behavior and request critical feedback on their actions. Mutual assessment and evaluation must be the norm in every school. Schools should provide the necessary resources, time for joint work and hours for mentoring teachers to train colleagues. Wagner (2003) also believes that small schools manage better to effectively involve parents; community members and partners work with the students all kinds of plans. This extended community, which has close relationships with adults and students, is an essential part of current educational needs. The teachers themselves will not be able to resolve the problem of motivation of all students to achieve better and therefore strive for smaller units in the one school building as small autonomous schools within larger schools, where groups of adults will work with a small group of students and their parents for lengthy periods of time. These units will allow teachers to work with greater collaboration, to know their students well and adjust their instruction and the content needs. Educational leaders know that the key to change is to motivate mixed groups to study and solve problems together. They ask questions but do not provide simple answers. They want constructive criticism, talking about their errors and, above all, demonstrate good instruction every single day.

\subsection{From Management to Leadership}

Defining the concept of the leader is not uniform. Some define it according to properties, others according to the role or position. The leader is seen, typically, as a person in a group with far greater impact in determining the goals and functions, and is chosen openly or covertly by members of the group. Leadership is an essential tool for organizations. The need for successful leadership and the difficulty finding it increases as that organization's environment is more complex and variable. Leadership is the ability to develop ideas and vision, influencing others to adopt the values and take tough decisions about people and other resources. Tichy (2002) defines leadership as the "ability to achieve something through other people that could not be obtained if you weren't there. In today's world, you can do so less and less by using commands and control and more and more by changing people's opinion on something and thus change behavior. Leadership is the ability to move ideas and values that motivate other people".

A leader is someone who fills the main roles of leadership: vision, values, ideas, influencing others and decisionmaking. On the other hand, the role of a principal is to be responsible for others and their work. Effective principals bring a high level of order and consistency to their employees.

The subject of leadership and its development occupied scientists and philosophers for many generations. This is an elusive concept that is difficult to define precisely. Today leadership is considered the ability for specialization - there are many types, each of which corresponds to another type of situation. For example, a person who succeeded as a military leader cannot necessarily succeed as Prime Minister or CEO of a high-tech company.

Burns (1978) claims leadership is one of the most frequent phenomena in every society, but is still among the least understood. "We know much about leaders and their work, but too little about the phenomenon of leadership".

Yukl (1994) argues that the main ingredient the leader has, as he attempts to lead others to a common group goal, is the ability to influence. The effect is an expression that everyone tends to understand and interpret intuitively but the influence of one on another can be done in several ways. The impact could be on the people (attitudes, perceptions and behaviors), or on events. The strength of the impact can be expected or unexpected, and the results may be suitable to expectations or deviate from them.

The impact process assumes that the audience is a necessary condition for leadership. People tend to do as leaders who will help them achieve their goals demand, and leaders must be aware of the extent of their motivation on the individual. In order to build trust between leader and the led, and so that the leader be received by the latter, a state of knowledge and understanding of employee behavior should be generated. Thus the leader arouses in his followers the motivation to act for organizational goals, while he assures its suitability between the individual's and the organization's objectives, creating a supportive atmosphere and cooperation between the workers in an organization.

Evans (2001) emphasizes the importance of logic in leadership. He defines leaders as affecting the enthusiasm of others. They build bridges which will take us from where we are to where we would not go without them. Leaders create commitment. They provide inspiration and are not afraid to make an effort. They create an atmosphere where others can succeed, and it is possible to do more, get more, want to give more than they could without their leadership.

Sofer, Katz \& Altan (1995) argue that the concept of leadership development relies on two basic premises:

Leadership can only be developed amongst people with suitable personality and motivation that lead and influence - that is, not everyone can develop leadership. Only people with special ability that embraces leadership potential can become leaders in the future

Leadership develops at all times and under all circumstances, i.e., a leader never stops learning from his and others' deeds.

Leadership development can be described in three dimensions or variables:

- Developing a sense of self-efficacy in the field of leadership - development of personal belief in the ability to motivate and influence others. This belief comes from two main factors:

- Internalizing implementational successes to the extent 
that chance failure does not change the perception of capability that brings a feeling of control

- Observing others ("if they managed to cope, so can I...")

- Developing self-awareness of leadership styles and personal attributes that affect motivating people - such development relies on more basic conditions of selflearning that allow recognizing the self and improving oneself accordingly .

- Developing leadership skills - such as interpersonal communication (listening, giving feedback, conversation), assertiveness, setting objectives and programs for their realization, decision-making and so on. Learning at this level usually occurs in workshops which allow intensive feedback and acquiring techniques.

For an organization to become a system that develops such leadership, four mandatory conditions must exist:

1. Organizational culture based on values and messages conveyed from top down, that encourage learning, experience and constant improvement, and are based on the individual's belief in his ability to develop;

2 . The clear definition of the desired leadership characteristics, such as content, values, objectives and impact of corporate leaders;

3. The existence of established training mechanisms (seminars and workshops providing knowledge, awareness and skills) and learning processes (through the ongoing connection in which the mentor helps the mentee to learn from examples, observation and investigation);

4. Organizational structuring - general organizational processes that support leadership-development processes, such as defining organizational roles and procedure in relation to developing leadership, adapting leadership training to providing feedback to subordinates and principals regarding leadership, introducing instructional materials and professional literature on leadership development.

The settings we see here and their classification raise several questions:

1. Why does one person have leadership abilities and another lack them?

2. Personal qualities.

3. Leadership in action or behavior, i.e. capable of high impact.

4. Different role and different people.

5. Initiating structure: supplying the needs of the organization.

Bass \& Aviolo (1994) say a leader's behavior actually changes periodically, and grows and changes over time and culture. The leader characteristics can be different at different times; leadership is universal among all peoples and animals. They also separate the leader from leadership (a leader is one, and leadership is others who are led, i.e. the phenomenon) and claim there are reasons for leadership personality, attributes and situational factors.

According to the claim that there are countless definitions of the word 'leadership' the term can be divided into two main categories:
Table 1.

\begin{tabular}{|c|c|}
\hline Inborn attributes & Acquired attributes \\
\hline $\begin{array}{l}\text { Leadership as personality } \\
\text { and its impact }\end{array}$ & $\begin{array}{l}\text { Leadership as an alternative - } \\
\text { leader with power and control }\end{array}$ \\
\hline $\begin{array}{l}\text { A person with many desired } \\
\text { qualities - quality } \\
\text { and personality }\end{array}$ & Leadership as the art of reacting \\
\hline $\begin{array}{l}\text { Knowledge to apply techniques, } \\
\text { set stimuli that will produce } \\
\text { suitable reactions for the targets }\end{array}$ & $\begin{array}{l}\text { The ability to lead people to } \\
\text { attain the maximum with mini- } \\
\text { mum friction and greatest coop- } \\
\text { eration }\end{array}$ \\
\hline $\begin{array}{l}\text { Combination of attributes } \\
\text { enables the individual to } \\
\text { motivate } \\
\text { others to complete } \\
\text { a given task }\end{array}$ & $\begin{array}{l}\text { The ability to force the leaders } \\
\text { wishes on others, leading to } \\
\text { obedience, respect, loyalty and } \\
\text { cooperation }\end{array}$ \\
\hline \multicolumn{2}{|l|}{$\begin{array}{l}\text { A person with special attributes } \\
\text { moving towards a purpose } \\
\text { together with the group in a } \\
\text { defined fashion }\end{array}$} \\
\hline \multicolumn{2}{|l|}{$\begin{array}{l}\text { Leadership as a tool to attain } \\
\text { a goal }\end{array}$} \\
\hline $\begin{array}{l}\text { The first dynamic force that } \\
\text { arouses, motives, and adapts the } \\
\text { organization to achieve } \\
\text { the objectives. }\end{array}$ & \\
\hline
\end{tabular}

According to Yukl (1994) most of the definitions of the concept of leadership discuss the influence and varying disagreements:

1. How to investigate leadership: should this phenomenon be studied as pertaining to one person, and whether the phenomenon occurs because of a particular person (from the psychological perspective).

2 . The person did not create a phenomenon but the phenomenon has created the leader (holistic-sociological perspective).

3. Is the impact of the leader only on the process"organization" or should it exceed the organization.

4. Power - should the leader use force, or, is anyone using force not a leader?

5. Leadership and management - are they the same?

Disputes on the subject in Yukl's (1994) work indicate that he, like Bass \& Aviolo (1994), does not hold unequivocally with the claim that leadership is but an inborn or acquired attribute. They all mention the combination of the two features together. Bass \& Aviolo (1994) state that there are reasons for leadership - the leadership personality, the attributes and elements in one situation and the circumstances leading to the phenomenon.

In his article Yukl (1994) mentions Stogdil (1974) who concludes that the number of different definitions of leadership is as the number of people trying to define it. Leadership is defined in terms of individual features (inborn), behavior (acquired) and influence on human beings. Stog- 
dil (1984) realizes that leadership does not depend on a fixed system of features, but the qualities, characteristics and skills needed by a leader are determined largely by situation in which he functions - as a leader.

From here we see the combination of the two features the inborn and the acquired - of the concept of leadership. One must remember the situation in which it is manifested. Mumford (2002) claims leaders developed since they had both inborn and acquired features and also grew in status as they resolved issues.

There are different styles of leadership, distinct from each other through three main factors:

1. Leader perceptions of his role and authority.

2. Company perceptions of leadership roles

3. Exposure of the leader to his employees

It can be said that the success of the leader largely depends on matching his leadership style to the circumstances he should lead.

\section{Conclusions}

Schools of the $21^{\text {st }}$ century now develop the managers of the next century and hence the need to "switch gear" in all respects and, as proposed by West-Burnham (2009), "from improvement to a sweeping change". Leadership will not change if our approach is random; we need a planned, integrated approach of school leaders of today and tomorrow, have the professional knowledge, skills, skill, prudence, sharp analysis and diagnosis, as well as sensitivity and intelligence. The current trends in school leadership present larger requirements than ever before. They also require of the school leadership - educators, trainers, instructors, policy-makers - to ensure the leaders will study ways to cause the development of elaborate capabilities.

\section{References}

[1] Bass, B.M. \& Avolio, B.J. (Eds.) (1994) Improving Organizational Effectiveness. Sage.

[2] Ben Zvi, H. (2006). Transformational leadership and the Pygmalion effect. Messages, organizational consulting and human resource development, community development, development.

[3] Burns, J. M. (1978). Leadership. In: R. Bugler (Ed.), 2000, Leadership and its applications in education. Tel Aviv: The Open University.
[4] Carmi M, (2004), Teachers in the classroom - Leaders in chemistry. The Chemistry, 5, pp. 33.

[5] Cheng, Y.C. (1993). An investigation of the relationship between classroom environment and students' affective performance. Paper presented at the Annual Conference of the American Educational Research Association, Atlanta, G.A.

[6] Evans, J. P. (2001). Commonsense leadership for uncommon times. Academic Leadership, 1 (2).

[7] Friedman, Y. (1995). School climate and class climate: Professional literature survey. Jerusalem: Szold Institute. (Hebrew).

[8] Hofstein, A., Carmi, M., \& Ben-Zvi, R. (2003). Developing leadership among chemistry teachers in Israel. International Journal of Science and Mathematics Education, 1(1), 39-65.

[9] Huber, S.G. (2004). School leadership and leadership development: Adjusting leadership theories and development programs to values and the core purpose of school.

[10] Mumford, M.D. (2009). Leadership 101, Springer Publishing Company, NY.

[11] Peleg, S., (2012), Leadership in education. PhD thesis research. Universities of Baber-Bolyai, Cluj Napoca, Romania.

[12] Sofer, M., Katz, N., \& Altan, A. (1995). Leading leadership keys - theory and practice. Pituach Irguni BeYisrael, 8, 2228. (Hebrew).

[13] Stogdill, R.M. (1974). Handbook of leadership: A survey of the literature, New York: Free Press.

[14] Tichy, N. M. (2002). The cycle of leadership. Harper Business Review.

[15] Wagner, C. (2000). School culture analysis. Address presented at the annual meeting of the Manitoba Association of Resource Teacher (MART). Winnipeg, Manitoba.

[16] West-Burnham, J. (2002). Leadership and spirituality. NCSL Leading Edge Seminar Think-piece www. ncsl.org.uk / leadingedge.

[17] West-Burnham, J. (2009). Rethinking educational leadership: From improvement to transformation. London: Continuum.

[18] Yukl, G.A. (1994). Leadership in organizations (3rd ed.) Englewood Cliffs, NJ: Prentice-Hall.

[19] Stefanowski, J. (1998). On rough set based approaches to induction of decision rules, in: L. Polkowski \& A. Skowron (Eds.), Rough Sets in Knowledge Discovery, PhysicaVerlag, Heidelberg, 500-529. 